\title{
Changes of lipid metabolism of Arabidopsis thaliana in response to oligochitosan treatment
}

\author{
X.J. WANG ${ }^{1}$, X.L. $\mathrm{SU}^{2}$, J.M. LI ${ }^{1 *}$, and P. $\mathrm{ZHU}^{3}$ \\ Zhejiang Provincial Key Laboratory of Plant Evolutionary Ecology and Conservation, Taizhou University, \\ Taizhou, Zhejiang 318000, P.R. China ${ }^{1}$ \\ College of Medicine, Zhejiang University, Hangzhou, Zhejiang 310003, P.R. China ${ }^{2}$ \\ Key Laboratory of Applied Marine Biotechnology, Ningbo University, Ningbo, Zhejiang 315211, P.R. China ${ }^{3}$
}

\begin{abstract}
Lipids are vital cellular constituents in plant, and lipid peroxidation metabolites are critical defence substances in plants. In this study, mass spectrometry along with projections to latent structures discriminant analysis (PLS-DA) was used to detect lipid metabolism changes in Arabidopsis thaliana in response to oligochitosan (an effective resistance elicitor for the control of plant diseases). The PLS-DA showed that lipid metabolites of Arabidopsis thaliana were influenced by oligochitosan treatment. The total content of oxylipin containing monogalactosyldiacylglycerols, oxylipin-containing digalactosyldiacylglycerols, and oxylipin-containing phosphatidylglycerols increased firstly (after $1 \mathrm{~h}$ ), and then decreased with the increase of oligochitosan treatment duration. In contrast, the total content of monogalactosyldiacylglycerols, phosphatidylcholines, phosphatidyl-ethanolamine, and phosphatidylglycerols decreased firstly, and then increased with the increase of oligochitosan treatment duration. The amounts of free fatty acids $(\mathrm{C} 16: 2, \mathrm{C} 16: 3, \mathrm{C} 18: 2$, and $\mathrm{C} 18: 3)$ were lower after treatment with oligochitosan for 1,3 , and $6 \mathrm{~h}$ than in the control, while the production of volatile organic compounds such as 2-hexenal (except for $3 \mathrm{~h}$ ) and nonanal was higher than in the control. In conclusion, lipid metabolites of Arabidopsis thaliana were influenced by oligochitosan treatment, and the synthesized lipids and oxylipin-containing lipids were remodelled and free fatty acids was metabolized to volatile organic compounds.
\end{abstract}

Additional key words: free fatty acids, oxylipin-containing lipids, volatile organic compounds.

\section{Introduction}

Lipids are vital cellular constituents that play important roles in transcriptional and translational control, cellular signalling, and cell-cell interactions (Wang 2004, Roberts et al. 2008). Galactolipids play an essential role in chloroplast development and the maintenance of electron transport systems, fatty acid synthesis, and photoreduction of cytochrome (Wang and Lin 2006). Phospholipids are major components of plasma membrane and organelle membranes that maintain the integrity of cells or organelles by creating a semi-impermeable barrier. Thus, lipid changes have impact on both cell structure and regulatory pathways during plant adaptations and survival. Lipid metabolism changes in plants are induced by various factors such as salinity, water stress, and extreme temperatures (Welti et al. 2002). Elkahoui et al. (2004) reported that phosphatidylcholine and phosphatidylethanolamine content increases and fatty acid composition is clearly modified when Catharanthus roseus is treated with $\mathrm{NaCl}$. Arabidopsis maintains its polar lipid content and composition under severe water stress (Gigon et al. 2004). Wang et al. (2006) reported that the content of phospholipids of Arabidopsis increases to enhance membrane fluidity and to reduce propensity of cellular membranes in response to low temperatures. Therefore, lipid metabolism plays an important role in response to changes in the external environment.

Submitted 19 February 2019, last revision 30 September 2019, accepted 23 October 2019.

Abbreviations: BHT - butylated hydroxytoluene; DGDG - digalactosyldiacylglycerol; FFAs - free fatty acids; lyso-DGDG - lysodigalactosyldiacylglycerol; lyso-MGDG - lyso-monogalactosyldiacylglycerol; lyso-PG - lyso-phosphatidylglycerol; MGDG - monogalactosyldiacylglycerol; PC - phosphatidylcholine; PE - phosphatidylethanolamine; PG - phosphatidylglycerol; PI phosphatidylinositol; PLS-DA - projections to latent structures discriminant analysis; UPLC - ultra performance liquid chromatography. Acknowledgments: This study was funded by the National Natural Science Foundation of China (grant No. 41606164), the Zhejiang Provincial Natural Science Foundation of China (No. LQ15D060001), the Open Fund of Zhejiang Provincial Top Key Discipline of Aquaculture in Ningbo University (No. xkzsc1418), and he Ecology Key Disciplines of Zhejiang Province in Taizhou University (No. EKD 2013-08). We appreciate Prof. Zhongnan Yang from the Shanghai Normal University to provide Arabidopsis thaliana (Col-1) seeds.

*Corresponding author; fax: (+86) 576 88660892; e-mail: lijmtzc@126.com 
Elicitors have no antimicrobial activity themselves, but they induce resistance or prime a plant for future pathogen attack (Liaqata and Eltem 2018). Elicitor also can induce lipid metabolic changes in plants. Kupper et al. (2006) reported that polysaccharides could induce the release of free saturated and unsaturated fatty acids and the accumulation of oxylipins in Laminaria digitata. Agarooligosaccharides induce changes of lipids metabolism in Pyropia haitanensis (Wang et al. 2014). As a type of biological elicitor, oligochitosan has been shown to be an effective resistance elicitor for the control of plant diseases (Yin et al. 2010). Oligosaccharides can induce gene expression and production of nitric oxide and $\mathrm{H}_{2} \mathrm{O}_{2}$ (Yin et al. 2006, Zhao et al. 2007a,b). Chen et al. (2009) reported that oligochitosan induces expression of gene for mosaic virus protein involved in resistance and pathogenesis in tobacco. However, oligochitosan induced changes of lipid metabolism are still not well understood in plants.

Arabidopsis thaliana, a small cruciferous plant, is an ideal model for investigating various aspects of higher plant biology including plant and pathogen interactions (Meyerowitz et al. 1991, Meinke et al. 1998, Mauch-Mani and Slusarenko 1993). In the present study, we analyzed the changes in lipids of $A$. thaliana treated with oligochitosan. The present study aimed at understanding the qualitative and quantitative changes of lipids in A. thaliana in response to oligochitosan treatment. The knowledge of glycerolipid changes of $A$. thaliana in response to an elicitor will facilitate the understanding of membrane lipids in plants.

\section{Materials and methods}

Chemicals and reagents: Acetonitrile, isopropanol, formic acid, and sodium formate for liquid chromatography-mass spectrometry (LC-MS) were purchased from SigmaAldrich (St. Louis, MO, USA). Distilled water was further treated with a Milli- $Q$ system (Millipore, Bedford, MA, USA). Leucine-enkephalin was purchased from Sigma-Aldrich. Standards of phosphatidylcholine (PC), phosphatidylglycerol (PG), phosphatidylethanolamine (PE), and phosphatidylinositol (PI) were obtained from the Avanti Polar Lipids (Alabaster, AL, USA). Glycolipid standards including monogalactosyldiacylglycerol (MGDG), digalactosyldiacylglycerol (DGDG) and sulfoquinovosyl-diacylglycerol (SQDG) were purchased from Lipid Products (Redhill, Surrey, UK). Oligochitosan (average Mr of 5 000) was purchased from Sigma-Aldrich.

Plants, growth conditions, and treatments: Arabidopsis thaliana L. (genotype Col-1) seeds were kindly provided as a gift by Professor Zhongnan Yang from Shanghai Normal University. Seeds of $A$. thaliana were geminated in growth chambers set at a temperature of $23 \pm 1{ }^{\circ} \mathrm{C}$, a $16-\mathrm{h}$ photoperiod, an irradiance of $144 \mu \mathrm{mol} \mathrm{m} \mathrm{m}^{-2} \mathrm{~s}^{-1}$, and a $70 \%$ relative humidity. The soil was Vermiculite: peat: Perlite $=6: 1: 0.5$. Thirty-day-old seedlings were used for further experiment.

Oligochitosan induction experiment was performed on 30-d-old $A$. thaliana plant. Oligochitosan solution at concentration $50 \mu \mathrm{g} \mathrm{cm}^{-3}$ was sprayed on the leaf of Arabidopsis thaliana to elicit defence responses. Samples were harvested at $0.5,1,3$, and $6 \mathrm{~h}$ after treatment. The control group was sprayed with sterile water. Six replicates were performed and the leaf samples were stored at $-80^{\circ} \mathrm{C}$ for analysis.

Lipid analysis: Briefly, $50 \mathrm{mg}$ of samples (freezedried) was extracted using chloroform/methanol/water (1:2:0.8, v/v/v) solution containing $0.05 \%(\mathrm{v} / \mathrm{v})$ butylated hydroxytoluene by a method reported by Bligh and Dyer (1959) with minor modifications. The samples were dried under nitrogen gas, and dissolved in methanol for ultra performance liquid chromatography-quadrupole-time of flight mass spectrometry (UPLC-qTOF-MS) analysis.

Chromatographic separation was performed on a ACQUI-TY UPLC BEH C8 analytical column $(100 \times$ $2.1 \mathrm{~mm}, 1.7 \mu \mathrm{m}$, Waters, Milford, MA) using a ACQUITY UPLC system (Waters). Optimal separation was achieved with a gradient elution using $\mathrm{A}$ - water containing $0.1 \%$ $(\mathrm{v} / \mathrm{v})$ formic acid and $0.01 \%(\mathrm{v} / \mathrm{v})$ lithium acetate; and $\mathrm{B}$ - a mixture of methanol: acetonitrile: isopropanol $(1: 2: 1$, $\mathrm{v} / \mathrm{v} / \mathrm{v}$, containing $0.1 \% \mathrm{v} / \mathrm{v}$ formic acid and $0.01 \%, \mathrm{v} / \mathrm{v}$, lithium acetate) at a flow rate of $0.45 \mathrm{~cm}^{3} \mathrm{~min}^{-1}$. The mobile phase $\mathrm{B}$ was held for $1 \mathrm{~min}$ at $5 \%$, then changed to $60 \%$ in $1 \mathrm{~min}$, reached $98 \%$ in $18 \mathrm{~min}$ and held for $5 \mathrm{~min}$, returned to the initial $5 \%$ in $1 \mathrm{~min}$ and equilibrated for $4 \mathrm{~min}$. The injection volume was $5 \mathrm{~mm}^{3}$. An aliquot of each sample was injected into the column and $25 \%$ of the effluent was split into the mass spectrometer. Mass spectrometry analysis was according to Wang et al. (2014) and Li et al. (2014).

Analysis of free fatty acids by gas chromatographymass spectrometry: Free fatty acids were extracted from the $A$. thaliana tissues according to Kupper et al. (2006) and dried under nitrogen gas. Fatty acids were methylated with boron trifluoride-methanol solution (14\% in methanol) for $1 \mathrm{~h}$ at $60^{\circ} \mathrm{C}$. The analysis of fatty acid esters was performed on an Agilent Technologies $7890 \mathrm{~A}$ gas chromatography system fitted with a $S P B-50$ fused capillary silica column $(30 \mathrm{~m} \times 0.25 \mathrm{~mm}, 0.25 \mu \mathrm{m}$; Supelco, Bellefonte, PA, USA) coupled with an Agilent Technologies $5975 \mathrm{C}$ mass spectrometer. The injection temperature was $250{ }^{\circ} \mathrm{C}$. After injection, the column temperature was kept at $100{ }^{\circ} \mathrm{C}$ for $3 \mathrm{~min}$, before being increased to $230{ }^{\circ} \mathrm{C}$ at a rate of $10{ }^{\circ} \mathrm{C}$ $\min ^{-1}$ and kept for $10 \mathrm{~min}$, and subsequently increased to a final temperature of $240{ }^{\circ} \mathrm{C}$ at a rate of $1{ }^{\circ} \mathrm{C} \mathrm{min}-1$ and kept for $10 \mathrm{~min}$. It was further increased to a final temperature of $280{ }^{\circ} \mathrm{C}$ at a rate of $5{ }^{\circ} \mathrm{C} \mathrm{min}-1$ and kept for $15 \mathrm{~min}$. The injection volume was $1 \mathrm{~mm}^{3}$ with a split ratio of 5:1. Mass spectrometry was operated under the electron impact mode with $70 \mathrm{eV}$ of electron energy. The ion source temperature and interface temperature were set at 230 and $220{ }^{\circ} \mathrm{C}$, respectively. The scan range was from $\mathrm{m} / \mathrm{z} 45$ to 450 . The individual substances were identified on the basis of their retention times by comparing their mass spectra with those recorded in Nist 11 and DEMO. L Spectrometry Library and those related to the previous analysis of pure 
references that are commercially available.

Analysis of volatile organic compounds by gas chromatography-mass spectrometry: The solid phase microextraction of $A$. thaliana tissues was conducted according to Croisier et al. (2010). A solid phase micro extraction (SPME) fiber (Supelco, Bellefonte, PA, USA) coated with an absorbent phase made of polydimethylsiloxane/carboxen/divinylbenzene (PDMS/CAR/DVB) was exposed in the headspace at $50 \pm 1{ }^{\circ} \mathrm{C}$ for $40 \mathrm{~min}$. After sampling, the fiber was analyzed using gas chromatography-mass spectrometry on an Agilent Technologies $7890 \mathrm{~A}$ gas chromatography system fitted with a Vocol column $(60 \mathrm{~m} \times 0.32 \mathrm{~mm}$, film thickness $1.8 \mu \mathrm{m}$; (Supelco) coupled with an Agilent Technologies $5975 \mathrm{C}$ mass spectrometer. The oven temperature was programmed as follows: $35^{\circ} \mathrm{C}$ for $3 \mathrm{~min}$, then to $40^{\circ} \mathrm{C}$ at $3{ }^{\circ} \mathrm{C} \mathrm{min}{ }^{-1}$ and held for $10 \mathrm{~min}$, finally to $210^{\circ} \mathrm{C}$ at $5^{\circ} \mathrm{C} \mathrm{min}^{-1}$ and held for $20 \mathrm{~min}$. The injection was splitless and the injector temperature was $210^{\circ} \mathrm{C}$. The mass spectra were obtained under electron ionization impact at $70 \mathrm{eV}$ and data acquisition was performed over an $\mathrm{m} / \mathrm{z}$ range of $50-600$. The analytes were identified on the basis of their retention times by comparing their mass spectra with those recorded in Nist 11 and DEMO. L Spectrometry Library and those related to the previous analysis of pure references that are commercially available.

Data analysis: All the data were shown as means \pm standard deviations (SDs). The preprocessing of UPLCMS data was performed with MarkerLynx 4.1 software (Waters, Milford, MA, USA). Pareto-scaled MarkerLynx matrices, including the peak number (based on the retention time and $\mathrm{m} / \mathrm{z}$ ), sample name, and the normalized peak intensity, were analyzed by projections to latent structures discriminant analysis (PLS-DA) using the SIMCA-P+ software package (v. 12.0, Umetrics AB, Umetric, Umea, Sweden). For each sampling time, differences between the treatments and control were analyzed via one-way analysis of variance $(A N O V A)$ and the Duncan multiple comparison test. Different lowercase letters were considered statistically significant at level $P<0.05$. Analysis was undertaken using SPSS 13.0 (SPSS, Chicago, IL, USA) for Windows.

\section{Results}

Fourteen MGDGs (mainly $\mathrm{C}_{18: 3} / \mathrm{C}_{16: 3}, \mathrm{C}_{18: 4}-\mathrm{O} / \mathrm{C}_{16: 4}-\mathrm{O}$, and $\mathrm{C}_{18: 3} / \mathrm{C}_{18: 3}$ ), 3 lyso-MGDGs, 5 DGDGs (mainly $\mathrm{C}_{18: 3} / \mathrm{C}_{18: 3}$, $\mathrm{C}_{18: 3} / \mathrm{C}_{16: 0}$, and $\mathrm{C}_{18: 3} / \mathrm{C}_{16: 3}$ ), 1 lyso-DGDG, 5 SQDGs (mainly $\mathrm{C}_{16: 0} / \mathrm{C}_{18: 2}$ ), 11 PGs (mainly $\mathrm{C}_{16: 0} / \mathrm{C}_{18: 1}$ and $\mathrm{C}_{16: 1} / \mathrm{C}_{18: 3}$ ), 1 lyso-PG, 5 PCs (mainly $\mathrm{C}_{18: 3} / \mathrm{C}_{18: 2}$ ), 6 PEs (mainly $\mathrm{C}_{18: 3} /$ $\mathrm{C}_{18: 2}$ ), 2 lyso-PEs, and 2 PIs were identified in the control Arabidopsis plants and plants treated with oligochitosan (Table 1 Suppl.). There was no difference in composition of MGDGs, lyso-MGDGs, DGDGs, lyso-DGDG, SQDGs, PGs, lyso-PG, PCs, PEs, lyso-PEs and PIs among control group and treatment groups after 1,3 , and $6 \mathrm{~h}(P>0.05)$.

Using positive and negative ion scan modes, lipid metabolic changes of control and treatment groups were analyzed with PLS-DA (Fig. 1 Suppl.). The samples were classified into three clusters: lipid metabolic changes in A. thaliana treated with oligochitosan for $0.5 \mathrm{~h}, 3 \mathrm{~h}$, and the control group were classified into one cluster, while lipid metabolic changes in A. thaliana treated with oligochitosan for $1 \mathrm{~h}$ or $6 \mathrm{~h}$ were classified into two separate clusters, respectively. The PLS-DA loading plot showed that oligochitosan treatment had an effect on the lipid profile of Arabidopsis thaliana.

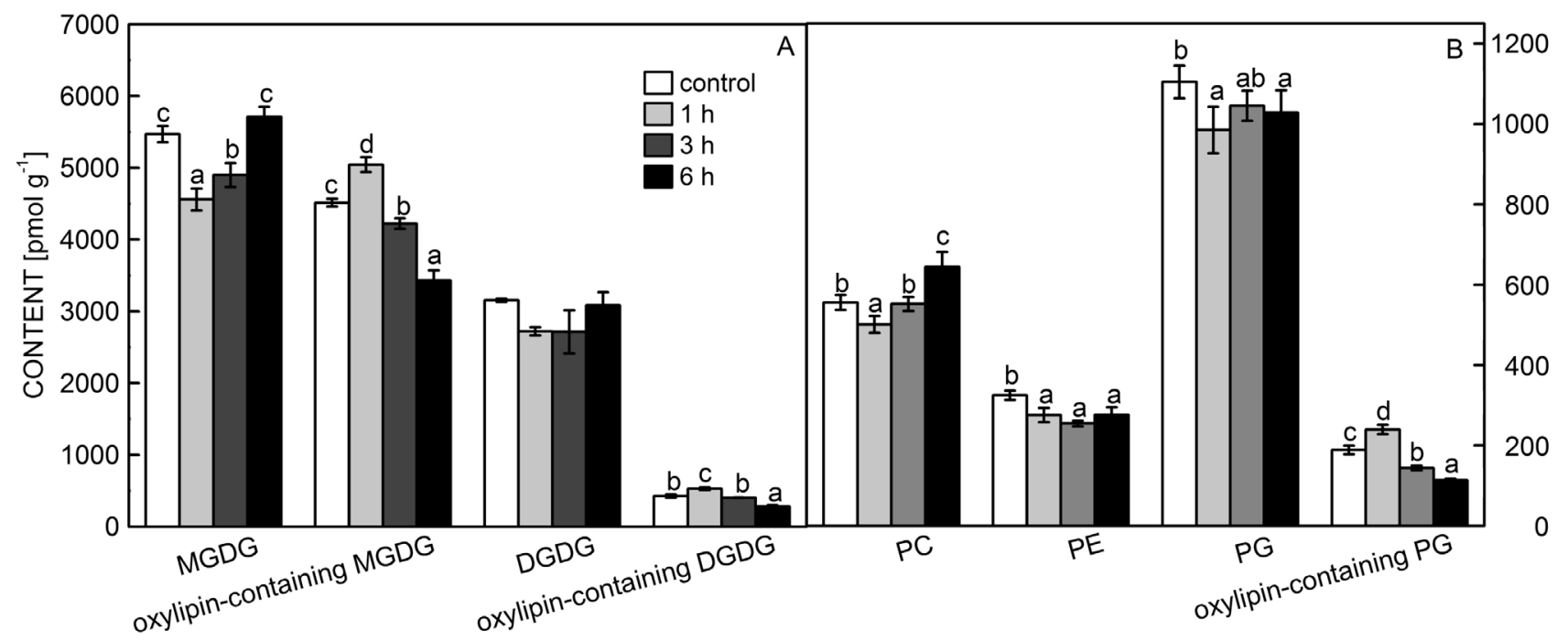

Fig. 1. Effects of oligochitosan treatment on glycerolipids in Arabidopsis thaliana. A - galactolipids: monogalactosyldiacylglycerols (MGDGs), digalactosyldiacylglycerols (DGDGs), oxylipin-containing MGDGs, and oxylipin-containing DGDGs; B - phospholipids: phosphatidylcholins (PCs), phosphatidylethanolamines (PEs), phosphatidylglycerols (PGs), and oxylipin-containing PGs. A. thaliana without treatment was used as a control and compared to plants treated with $50 \mu \mathrm{g} \mathrm{cm}^{-3}$ oligochitosan for 1,3 , and $6 \mathrm{~h}$. Means $\pm \mathrm{SDs}$, $\mathrm{n}=6$. Different lowercase letters indicate significant differences (the Duncan's test, $\mathrm{P}<0.05$ ). 


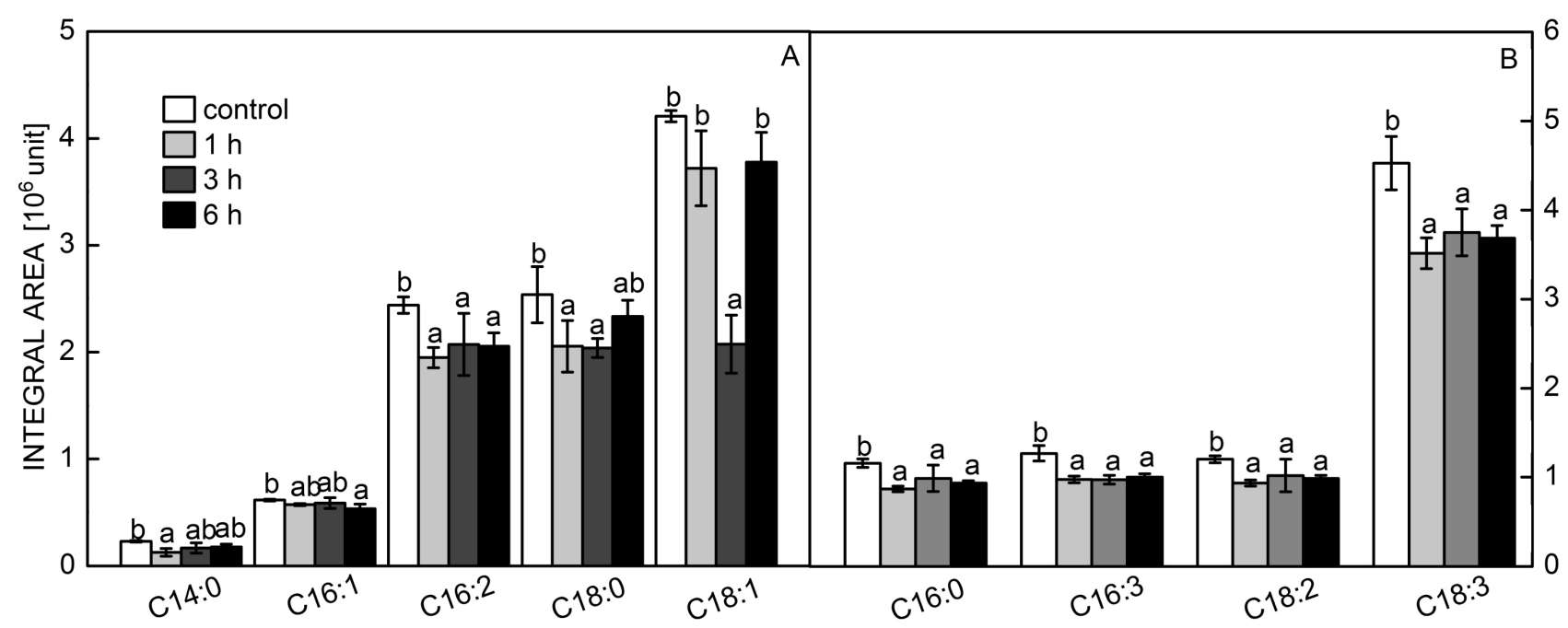

Fig. 2. Effects of oligochitosan treatment on the content of free fatty acids in Arabidopsis thaliana. Plants without treatments were used as controls and compared to those treated with $50 \mu \mathrm{g} \mathrm{cm}^{-3}$ oligochitosan for 1, 3, and $6 \mathrm{~h}$. A - C14:0, C16:1, C16:2, C18:0, and C18:1; $\mathrm{B}-\mathrm{C} 16: 0, \mathrm{C} 16: 3, \mathrm{C} 18: 2$, and C18:3. Means $\pm \mathrm{SDs}, \mathrm{n}=6$. Different lowercase letters indicate significant differences (the Duncan's test, $\mathrm{P}<0.05$ ).

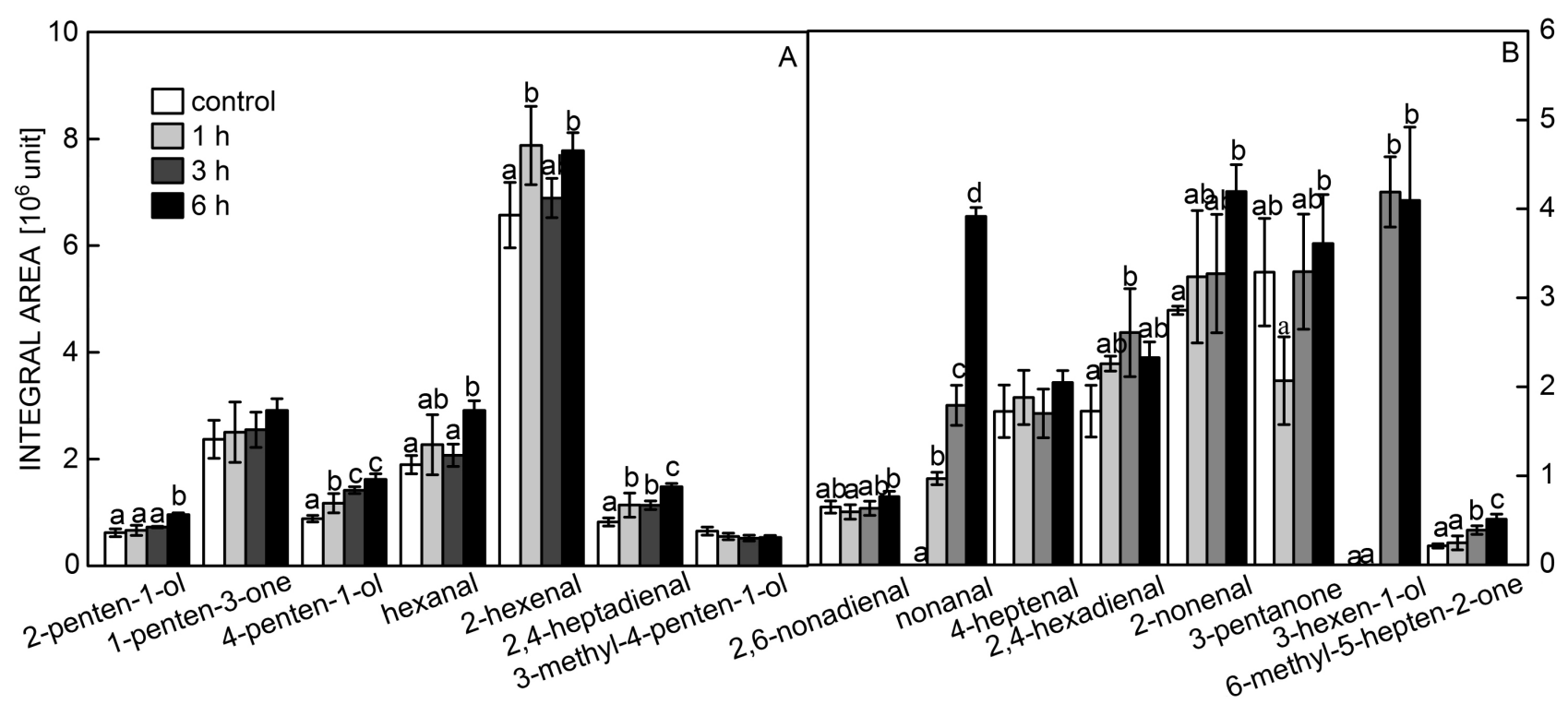

Fig. 3. Effects of oligochitosan treatment on the amounts of volatile organic compounds in Arabidopsis thaliana. Plants without treatments were used as controls and compared to those treated with $50 \mu \mathrm{g} \mathrm{cm}^{-3}$ oligochitosan for 1 , 3, and $6 \mathrm{~h}$. A - 2-penten-1ol, 1-penten-3-one, 4-penten-1-ol, hexanal, 2-hexenal, 2,4-heptadienal, and 3-methyl-4-penten-1-ol. B - 2,6-nonadienal, nonanal, 4-heptenal, 2,4-hexadienal, 2-nonenal,3-pentanone, 3-hexen-1-ol, and 6-methyl-5-hepten-2-one. Means \pm SDs, $\mathrm{n}=6$. Different lowercase letters indicate significant differences (the Duncan's test, $\mathrm{P}<0.05$ ).

ESI-MS/MS was used to analyze the changes of lipids in A. thaliana treated with oligochitosan (Table 1 Suppl. and Fig. 1). The total content of MGDGs decreased with oligochitosan treatment for $1 \mathrm{~h}(P<0.05)$, and then gradually increased after treatment for $3 \mathrm{~h}(P<0.05)$, finally returned to the control level after oligochitosan treatment for $6 \mathrm{~h}(P<0.05)$. Compared to the control, the total content of oxylipin-containing MGDGs, oxylipin-containing DGDGs, and oxylipin-containing PGs increased after treatment with oligochitosan for $1 \mathrm{~h}$ $(P<0.05)$, and then decreased and were lower after 3 and
$6 \mathrm{~h}$ than in control group $(P<0.05)$. No difference was found in total DGDGs content in all groups.

The total amount of PEs and PGs in A. thaliana treated with oligochitosan for $1,3 \mathrm{~h}$ (except for PGs), and $6 \mathrm{~h}$ were lower than those in control group $(P<0.05)$, while no differences were found among oligochitosan treated groups $(1,3$, and $6 \mathrm{~h} ; P>0.05)$. The total PC content decreased with oligochitosan treatment for $1 \mathrm{~h}(P<0.05)$, and then gradually increased after 3 and $6 \mathrm{~h}$, and the PCs content after $6 \mathrm{~h}$ was higher than in control group $(P<0.05)$.

Nine types of fatty acids (C14:0, C16:0, C16:1, C16:2, 
$\mathrm{C} 16: 3, \mathrm{C} 18: 0, \mathrm{C} 18: 1, \mathrm{C} 18: 2$, and $\mathrm{C} 18: 3)$ in control and treated groups were identified (Fig. $2 A, B$ ). The $\mathrm{C} 18: 3$ was the most abundant species, followed by $\mathrm{C} 16: 3$ and $\mathrm{C} 18: 2$ in both control and treated groups. The content of free fatty acids C16:0, C16:2, C16:3, C18:,2 and C18:3 was lower in groups terated with oligochitosan for 1,3 , and $6 \mathrm{~h}$ than in control $(P<0.05)$, while there were no differences among oligochitosan treated groups $(1,3$, and $6 \mathrm{~h})(P>0.05)$. The content of fatty acid C18:1 in plants treated with oligochitosan for $3 \mathrm{~h}$ was lower than in control and other treatments, while there was no difference in C18:1 content between control and groups treated for 1 and $6 \mathrm{~h}$ $(P>0.05)$. The C14:0 content in $A$. thaliana treated with oligochitosan for $1 \mathrm{~h}$ was lower than in control $(P<0.05)$, while there was no difference among those treated for $3 \mathrm{~h}$, $6 \mathrm{~h}$, and control $(P>0.05)$. The C18:0 content in plants treated with oligochitosan for 1 and $3 \mathrm{~h}$ was lower than in control $(P<0.05)$, while there was no difference between those treated for $6 \mathrm{~h}$ and control $(P>0.05)$. The content of C16:1 fatty acid in $A$. thaliana treated with oligochitosan for $6 \mathrm{~h}$ was lower than in control $(P<0.05)$, while there was no difference in among $1 \mathrm{~h}, 3 \mathrm{~h}$, and control $(P>0.05)$.

Eight aldehydes, 3 ketones, and 4 alcohols were identified in both the treatment and control groups (Fig. 3A,B). 2-hexenal was the dominant volatiles in $A$. thaliana in all groups (Fig. $3 A$ ). Compared to the control, a number of volatile organic compaunds increased after treatment with oligochitosan (Fig. 3). The content of 4-penten-1-ol, 2-hexenal, 2,4-heptadienal, and nonanal in the groups treated for 1, 3 (except for 2-hexenal), and $6 \mathrm{~h}$ were higher than in control group $(P<0.05)$. The content of 3-hexen-1-ol and 6-methyl-5-hepten-2-one in the group treated for for 3 and $6 \mathrm{~h}$ was higher $(P<0.05)$ than that in the group treated for $1 \mathrm{~h}$ and control group. The content of 2-nonenal, 2-penten-1-ol, and hexanal in the group treated for $6 \mathrm{~h}$ was higher than that in groups treated for 1 or $3 \mathrm{~h}$ and in control group $(P<0.05)$.

\section{Discussion}

Lipid metabolism changes can be induced by elicitors and stress (Pohnert 2002). In the present study, PLS-DA loading plot showed that oligochitosan treatment had an effect on the lipid profile of Arabidopsis thaliana. PLADA scores scatter plot showed that the metabolite profiles of $A$. thaliana in the control, and treatments groups (with oligochitosan for $0.5,1,3$, and $6 \mathrm{~h}$ ) can be classified into three clusters, suggesting that the lipid metabolism of A. thaliana was changed by oligochitosan. Moreover, the control group was clustered together with the groups treated with oligochitosan for 0.5 and $3 \mathrm{~h}$. However, the lipid profile among the control group, group treated with oligochitosan for $1 \mathrm{~h}$ and group treated with oligochitosan for $6 \mathrm{~h}$ were significantly different. The results indicated that the oligochitosan did not cause lipid changes after $0.5 \mathrm{~h}$, but the lipids started to change after $1 \mathrm{~h}$, and then returned to the levels of the control group after $3 \mathrm{~h}$. Interestingly, the lipids started to change again after $6 \mathrm{~h}$.

Following biotic and abiotic stress, lipids can release
FFAs (including free saturated fatty acids and free unsaturated fatty acids), and then the FFAs can be oxidized into a wide range of metabolites. The lipids can also be directly oxidized into oxylipin-containing lipids (Genva et al. 2018). In this study, the total amount of oxylipincontaining glycolipids (MGDGs and DGDGs) and oxylipin-containing PGs increased at $1 \mathrm{~h}$ after treatment with oligochitosan; however, glycolipids (MGDGs), PGs, and FFAs (C14:0, C16:0, C16:2, C16:3, C18:0, $\mathrm{C} 18: 2$ and $\mathrm{C} 18: 3$ ) decreased at the same time. The results suggested that the synthesized glycerolipids were oxidized to oxylipin-containing glycerolipids, rather than they released FFAs in response to oligochitosan treatment.

Plants produced high amount of oxylipin-containing lipids under stress conditions (Genva et al. 2018). Buseman et al. (2006) found that the content of oxylipin-containing lipids (glycerolipids containing oxophytodienoic acid and dinor-oxophytodienoic acid) was higher in Arabidopsis wounded leaves than in control ones. The rapid formation (2 - 30 min) of linolipins $C$ and $D$ alongside with linolipins $\mathrm{A}$ and $\mathrm{B}$ occurred in the flax leaves upon their damage by freezing-thawing (Chechetkin et al. 2013). Wang et al. (2017) demonstrated that the content of oxylipincontaining MGDGs, oxylipin-containing DGDGs, and oxylipin-containing PGs in $A$. thaliana increased with the increased time after infection with Sclerotinia sclerotiorum. Total amount of oxylipin-containing DGDGs and MGDGs of $A$. thaliana leaves increased 5- to 6-fold at $45 \mathrm{~min}$ after wounding (Vu et al. 2014), while oligochitosan changes were much lower in $A$. thaliana after treatment with oligochitosan for $1 \mathrm{~h}(P<0.05)$ in this study. The results indicated that oligochitosan was a protective elicitor, not an injury signal. With the increased time of treatment with oligochitosan, the total content of oxylipin-containing glycolipids (MGDGs and DGDGs) and oxylipin-containing PGs decreased at 3 and $6 \mathrm{~h}$, and it was lower than that in the control group. These results could be explained as a strategy of protection against oxidative damage through membrane restructuration with less oxylipin-containing glycolipids (Bejaoui et al. 2016).

Free mono- and polyunsaturated fatty acids are further converted to short chain volatile components (Feussner and Wasternack 2002, Stumpe et al. 2006). For example, C18:2 and C18:3 fatty acids are converted into hexanal, 2-hexenal or 3-hexenal, and 2-nonenal or 2,6-nonadienal (Matsui et al. 2006, Gigot et al. 2010). In this study, we found that the content of free fatty acids (C16:2, $\mathrm{C} 16: 3, \mathrm{C} 18: 2$, and $\mathrm{C} 18: 3)$ in A. thaliana after treatment with oligochitosan $(1,3$, and $6 \mathrm{~h})$ was lower than that in control, suggesting that the released FFAs might be further metabolized, resulting in the decline of their relative content. The emission of volatile organic compounds was observed in this study. For example, the content of 2-hexenal and nonanal in $A$. thaliana after treatment with oligochitosan for 1, 3 (except for 2-hexenal), and $6 \mathrm{~h}$ was higher than in the control group. Thus, the FFAs (C16:2, C16:3, C18:2, and C18:3) would be metabolized to volatile organic compounds in response to oligochitosan treatment.

Most plant volatile organic compounds have bacteriostatic activity, which act as plant resistance and 
chemical defense factors against pathogen infection (Scala et al. 2013). Vaughn and Gardner (1993) reported that 2-hexenal and 2-nonenal inhibit growth of Rhizoctonia solani and Sclerotium rolfsii. Kishimoto et al. (2006) reported that 2-hexenal enhances resistance of Arabidopsis thaliana against a necrotrophic pathogen Botrytis cinerea. Nonanal, 2-nonenal, and 2,6-nonadienal have fungicidal activities against Botrytis cinerea and Fusarium oxysporum (Matsui et al. 2006). In this study, we also found that amount of these volatile organic compounds increased. For example, 2-nonenal and hexanal content in A. thaliana after treatment with oligochitosan for $6 \mathrm{~h}$ was higher than that in control group, suggesting that some volatile compounds could participate in the induction of resistance in $A$. thaliana.

In summary, the lipid metabolism was activated in response to oligochitosan treatment, as shown by the changes in glycerolipids and oxylipin-containing glycolipids, via decreasing the FFAs content and increasing content of volatile organic compounds.

\section{References}

Bejaoui, F., Salas, J.J., Nouairi, I., Smaoui, A., Abdelly, C., Martínez-Force, E., Youssef, N.B.: Changes in chloroplast lipid contents and chloroplast ultrastructure in Sulla carnosa and Sulla coronaria leaves under salt stress. - J. Plant Physiol. 198:32-38, 2016

Bligh, E.G., Dyer, W.J.: A rapid method of total lipid extraction and purification. - Can. J. Biochem. Physiol. 37: 91-917, 1959.

Buseman, C.M., Tamura, P., Sparks, A.A., Baughman, E.J., Maatta, S., Zhao, J., Roth, M.R., Esch, S.W., Shah, J., Williams, T.D., Welti, R.: Wounding stimulates the accumulation of glycerolipids containing oxophytodienoic acid and dinoroxophytodienoic acid in Arabidopsis leaves. - Plant Physiol. 142: 28-39, 2006.

Chechetkin, I.R., Blufard, A.S., Khairutdinov, B.I., Mukhitova, F.K., Gorina, S.S., Yarin, A.Y., Antsygina, L.L., Grechkin, A.N.: Isolation and structure elucidation of linolipins $\mathrm{C}$ and D, complex oxylipins from flax leaves. - Phytochemistry 96:110-116, 2013

Chen, Y.F., Zhan, Y., Zhao, X.M., Guo, P., An, H.L, Du, Y.G,, Han,Y.R., Liu, H., Zhang, Y.H.: Functions of oligochitosan induced protein kinase in tobacco mosaic virus resistance and pathogenesis related proteins in tobacco. - Plant Physiol. Biochem. 47: 724-731, 2009.

Croisier, E., Rempt, M., Pohnert, G.: Survey of volatile oxylipins and their biosynthetic precursors in bryophytes. Phytochemistry 71: 574-580, 2010.

Elkahoui, S., Smaoui, A., Zarrouk, M., Ghrir, R., Limam, F.: Salt-induced lipid changes in Catharanthus roseus cultured cell suspensions. - Phytochemistry 65: 1911-1917, 2004.

Feussner, I., Wasternack, C.: The lipoxygenase pathway. - Annu. Rev. Plant Biol. 53: 275-297, 2002.

Genva, M., Akong, F.O., Andersson, M.X., Deleu, M., Lins, L., Fauconnier, M.L.: New insights into the biosynthesis of esterified oxylipins and their involvement in plant defense and developmental mechanisms. - Phytochem. Rev. ??: 1-16, 2018.

Gigon, A., Matos, A.R., Laffray, D., Zuilyfodil, Y., Phamthi, A.T.: Effect of drought stress on lipid metabolism in the leaves of Arabidopsis thaliana (ecotype Columbia). - Ann. Bot. 94:
345-351, 2004.

Gigot, C., Ongena, M., Fauconnier, M.L., Wathelet, J.P., Jardin, P. D., Thonart, P.: The lipoxygenase metabolic pathway in plants: potential for industrial production of natural green leaf volatiles. - Biotechnol. Agron. Soc. Environ. 14: 451-460, 2010.

Kishimoto, K., Matsui, K., Ozawa, R., Takabayashi, J.: Components of C6-aldehyde-induced resistance in Arabidopsis thaliana against a necrotrophic fungal pathogen, Botrytis cinerea. - Plant Sci. 170: 715-723, 2006.

Kupper, F.C., Gaquerel, E., Boneberg, E.M., Morath, S., Salaun, J.P., Potin, P.: Early events in the perception of lipopolysaccharides in the brown alga Laminaria digitata include an oxidative burst and activation of fatty acid oxidation cascades. -J. exp. Bot. 57: 1991-1999, 2006.

Li, S., Xu, J.L., Chen J, Chen, J.J., Zhou, C.X., Yan, X.J.: The major lipid changes of some important diet microalgae during the entire growth phase. - Aquaculture 428-429: 104-110, 2014.

Liaqata, F., Eltem, R.: Chitooligosaccharides and their biological activities: a comprehensive review. - Carbohydr. Polymers 184: 243-259, 2018.

Matsui, K., Minami, A., Hornung, E., Shibata, H., Kishimoto, K., Ahnert, V., Kindl, H, Kajiwara, T., Feussner, I.: Biosynthesis of fatty acid derived aldehydes is induced upon mechanical wounding and its products show fungicidal activities in cucumber. - Phytochemistry 67: 649-657, 2006.

Mauch-Mani, B., Slusarenko, A.J.: Arabidopsis as a model host for studying plant-pathogen interactions. -Trends Microbiol. 1: 265-270, 1993.

Meinke, D.W., Cherry, J.M., Dean, C., Rounsley S.D., Koornneef, M.: Arabidopsis thaliana: a model plant for genome analysis. - Science 282: 662-682, 1998.

Meyerowitz, E.M., Bowman, J.L., Brockman, L.L., Drews, G.N., Jack, T., Sieburth, L.E., Weigel, D.: A genetic and molecular model for flower development in Arabidopsis thaliana. Develompment 1 (Suppl.): 157-167, 1991.

Pohnert, G.: Phospholipase A2 activity triggers the woundactivated chemical defense in the diatom Thalassiosira rotula. - Plant Physiol. 129: 103-111, 2002.

Roberts, L.D., McCombie, G., Titman, C.M., Griffin, J.L.: A matter of fat: an introduction to lipidomic profiling methods. - J. Chromatogr. B. 871: 174-181, 2008.

Scala, A., Allmann, S., Mirabella, R., Haring, M. A., Schuurink, R.C.: Green leaf volatiles: a plant's multifunctional weapon against herbivores and pathogens. - Int. J. mol. Sci. 14: 17781-17811, 2013.

Stumpe, M., Bode, J., Göbel, C., Wichard, T., Schaaf, A., Frank, W., Frank, M., Reski, R., Pohnert, G., Feussner, I.: Biosynthesis of C9-aldehydes in the moss Physcomitrella patens. - Biochim. Bbophys. Acta. 1761: 301-312, 2006.

Vaughn, S.F., Gardner. H.W.: Lipoxygenase-derived aldehydes inhibit fungi pathogenic on soybean. -J. chem. Ecol. 19: 2337$2345,1993$.

Vu, H.S., Shiva, S., Roth, M.R., Tamura, P., Zheng, L., Li, M., Sarowar, S., Honey, S., McEllhiney, D., Hinkes, P., Seib, L., Williams, T.D., Gadbury, G., Wang, X., Shah, J., Welti, R.: Lipid changes after leaf wounding in Arabidopsis thaliana: expanded lipidomic data form the basis for lipid co-occurrence analysis. - Plant J. 80: 728-743, 2014.

Wang, X.J., Li, J.M., Zhu, P.: Effect of Sclerotinia sclerotiorum on lipid metabolism in Arabidopsis thaliana. - J. Plant Dis. Protect. 124: 421-426, 2017.

Wang, S.Y., Lin, H.S.: Effect of plant growth temperature on membrane lipids in strawberry (Fragaria $\times$ ananassa Duch.). - Sci. Hort. 108: 35-42, 2006. 
Wang, X.J., Su, X.L., Luo, Q.J., Xu, J.L., Chen, J.J., Yan, X.J., Chen, H.M.: Profiles of glycerolipids in Pyropia haitanensis and their changes responding to agaro-oligosaccharides. - $\mathrm{J}$. appl. Phycol. 26: 2397-2404, 2014.

Wang, X.M.: Lipid signaling. - Curr. Opin. Plant Biol. 7: 329336, 2004.

Wang, X.M., Li, W.Q., Li, M.Y., Welti, R.: Profiling lipid changes in plant response to low temperatures. - Physiol. Plant. 126: 90-96, 2006

Welti, R., Li, W., Li, M., Sang, Y., Biesiada, H., Zhou, H.E., Rajashekar, C.B., Williams, T.D., Wang, X.: Profiling membrane lipids in plant stress responses. Role of phospholipase D alpha in freezing-induced lipid changes in Arabidopsis. - J. biol. Chem. 277: 31994-32002, 2002.
Yin, H., Li, S., Zhao, X., Du, Y., Ma, X.: cDNA microarray analysis of gene expression in Brassica napus treated with oligochitosan elicitor. - Plant Physiol. Biochem. 44: 910-916, 2006.

Yin, H., Zhao, X., Du, Y.: Oligochitosan: a plant diseases vaccine. A review. - Carbohydr. Polymers 82: 1-8, 2010.

Zhao, X.M., She, X.P., Du, Y.G., Liang, X.M.: Induction of antiviral resistance and stimulary effect by oligochitosan in tobacco. - Pestic. Biochem. Physiol. 87: 78-84, 2007a.

Zhao, X.M., She, X.P., Liang, X.M., Du, Y.G.: Effects of oligochitosans on tobacco cells and role of endogenous nitric oxide burst in the resistance of tobacco to Tobacco mosaic virus. - J. Plant Pathol. 89: 69-79, $2007 \mathrm{~b}$. 